\title{
Overexpression of the Aspergillus niger GatA transporter leads to preferential use of D-galacturonic acid over D-xylose
}

\author{
Jasper Sloothaak, Mike Schilders, Peter J Schaap and Leo H de Graaff*
}

\begin{abstract}
Pectin is a structural heteropolysaccharide of the primary cell walls of plants and as such is a significant fraction of agricultural waste residues that is currently insufficiently used. Its main component, D-galacturonic acid, is an attractive substrate for bioconversion. The complete metabolic pathway is present in the genome of Aspergillus niger, that is used in this study. The objective was to identify the D-galacturonic acid transporter in A. niger and to use this transporter to study D-galacturonic acid metabolism.

We have functionally characterized the gene An14g04280 that encodes the D-galacturonic acid transporter in A. niger. In a mixed sugar fermentation it was found that the An14g04280 overexpression strain, in contrast to the parent control strain, has a preference for D-galacturonic acid over D-xylose as substrate. Overexpression of this transporter in A. niger resulted in a strong increase of D-galacturonic acid uptake and induction of the D-galacturonic acid reductase activity, suggesting a metabolite controlled regulation of the endogenous D-galacturonic acid catabolic pathway.
\end{abstract}

Keywords: D-galacturonic acid; Pectin; Sustainable resources; Aspergillus niger; Transmembrane transport

\section{Introduction}

Global limits in food and energy availability are becoming a major concern. Arable land is needed for production of food and large waste streams come from processing of our largest food resources, like grain, maize, potato and rice. These waste streams are currently insufficiently exploited and mainly used for feed and energy production (Howard et al. 2003). Alternatively, agricultural waste streams can be used as substrate for fermentative production of chemicals by microorganisms.

Historically, Aspergillus species are used for the production of food additives and platform chemicals such as citric acid (A. niger) and itaconic acid (A. terreus) (Willke and Vorlop 2001). The filamentous fungus Aspergillus niger is additionally exploited for production of enzymes for food and feed applications, many of which have been rewarded the GRAS (Generally Recognized As Safe) status (Howard et al. 2003; van Dijck et al. 2003).

\footnotetext{
* Correspondence: leo.degraaff@wur.nl

Microbial Systems \& Synthetic Biology, Laboratory of Systems and Synthetic Biology, Wageningen University, Dreijenplein 10, NL-6703 HB, Wageningen,
} Netherlands
Grain, maize and rice waste stream material contains around $40 \%$ cellulose, 35\% hemicellulose, $20 \%$ lignin and $5 \%$ pectin, while waste streams from other plants, such as sugar beet and potato, contain around 20\% cellulose and hemicellulose, less than $1 \%$ lignin and $30 \%$ to $40 \%$ pectin (Ángel Siles López et al. 2010; Howard et al. 2003; Micard et al. 1996). A. niger has a high capacity for degrading the hemicellulose, pectin and, to a lesser extend, cellulose fractions as the genome of $A$. niger encodes multiple gene variants of the enzymes required for the efficient degradation of these polysaccharides. (van den Brink and de Vries 2011).

D-glucose and D-xylose, released from plant wall material, are carbon sources that will yield high energy upon being metabolized. The genome of $A$. niger is wired to specifically produce and secrete the enzymes involved in degradation of the cellulose and hemicellulose fractions to release $\mathrm{D}$-glucose and $\mathrm{D}$-xylose. These sugars are then taken up and metabolized, before energy is invested in the release of other carbon sources from polysaccharides. This preferential uptake is regulated by the interplay of activating and repressing transcription factors that

\section{勿}


respond to extracellular concentrations of inducers and sugars.

Expression of genes that code for enzymes involved in cellulose and hemicellulose degradation in $A$. niger is regulated by the transcription factor XlnR (Gielkens et al. 1999). $X \ln R$ is activated by inducers derived from xylan, like D-xylose, though at a higher concentration this activation is attenuated by CreA (de Vries et al. 1999; Ruijter et al. 1999; van Peij et al. 1998). Tight regulation of the specific genes encoding proteins involved in the release, uptake and metabolism of sugars gives the fungus the ability to utilize the available sugars in a physiologically most efficient way. However, circumventing this regulatory mechanism would potentially lead to simultaneous uptake of all sugar substrates and improved fermentation yields.

Genes encoding proteins involved in the degradation of pectin and the $\mathrm{D}$-galacturonic acid metabolic pathway are found to be highly upregulated when $A$. niger is growing in the presence of $\mathrm{D}$-galacturonic acid, in comparison to when the fungus is growing in the presence of Dglucose or D-fructose (Table 1). Three genes among the genes that are upregulated are coding for proteins with a strong similarity to transporters (Martens-Uzunova and Schaap 2008; van der Veen et al. 2009).

In this study we have functionally identified the Dgalacturonic mono-acid sugar transporter by overexpression in A. niger. The effect of the increased uptake of D-galacturonic acid on the preferential uptake and metabolism of substrates has been assessed by mixed sugar fermentations and enzyme activity measurements.

\section{Materials and methods}

\section{Strains}

All Aspergillus strains used are descendants of $A$. niger N400 (CBS 120.49). A niger strain NW185 cspA1, fwnA1, goxC17, prtF28) was derived from NW131 and has been described by Ruijter et al. 1999. The recipient strain in all transformation experiments NW186 ( $\triangle \operatorname{argB}$; pyrA6; prtF28; $\operatorname{gox} C 17$; $\operatorname{csp} A 1)$ is an $\arg B$ and $\operatorname{pyr} A$ derivative of NW185.

\section{Vector construction}

Primers used in the construction of vectors are summarized in Table 2. Plasmids used for transformations of $A$. niger were constructed according to the general scheme given in Figure 1. Martens-Uzunova and Schaap was the source for the selection of the putative transporters (Martens-Uzunova and Schaap 2008); An14g04280 and An03g01620 were obtained from the Aspergillus genome database (Arnaud et al. 2012; Pfaffl 2001). These sequences were used to synthesize the respective coding sequences that were modified to remove conflicting restriction sites (BaseClear, Leiden, Netherlands). The An07g00780 fragment was amplified by PCR using primers JS_gatC_FW and JS_gatC_RV and A. niger NW186 genomic DNA as template and was subcloned into a pJET1.2 vector (Thermo scientific). The BglII restriction site was removed from the coding sequence by using the Quikchange Lightning Site-directed mutagenesis kit (Agilent Technologies) with the primers JS_gatCmut2_FW and JS_gatCmut2_RV. The PCR fragments were cloned into a pUC19 derived expression vector under control of an modified $x \ln D$ promoter and the $x \ln D$ terminator of $A$. niger. Plasmids were propagated in DH5 $\alpha$ E. coli. The medium used for E. coli growth was LB $(10 \mathrm{~g} / \mathrm{L}$ Bacto tryptone, $5 \mathrm{~g} / \mathrm{L}$ Yeast extract, $10 \mathrm{~g} / \mathrm{L} \mathrm{NaCl}$ ) supplemented with $100 \mathrm{mg} / \mathrm{L}$ ampicillin when appropriate.

\section{Transformation of Aspergillus niger}

For the transformation of $A$. niger NW186, protoplasts were generated using Novozyme-234 lysing enzyme cocktail. The An14g04280, An03g01620 and An07g00780 constructs were introduced in $A$. niger by transformation (Kusters-van Someren et al. 1991) using the pyrA gene as a primary selection marker, relieving uridine auxotrophy. To generate the parent control reference strain, NW186 was transformed using pGW635, the resulting NW185 PYR $\mathrm{A}^{+}$strain was used as a control strain in our studies. Colonies were randomly picked from the primary transformation plates and re-plated on selective medium to purify the single colonies.

\section{Analysis of A. niger transformants}

Screening of randomly picked transformants was done by PCR on genomic DNA isolates. For that, fresh mycelium was disrupted using MP lysing matrix $\mathrm{C}$ tubes and $400 \mu \mathrm{l}$ DNA extraction buffer $(0.1 \mathrm{M}$ Tris $\mathrm{HCl} \mathrm{pH}$ 8.0, $1.2 \mathrm{M} \mathrm{NaCl}, 5 \mathrm{mM}$ EDTA). DNA was extracted using phenol-chloroform extraction. The pellet was washed with $70 \%$ cold ethanol, air-dried and re-suspended in $50 \mu \mathrm{MQ}$

Table 1 Data used for selection of putative D-galacturonic acid transporters (Martens-Uzunova and Schaap 2008)

\begin{tabular}{lllll}
\hline Locus tag & Functional annotation & \multicolumn{2}{l}{ Relative expression $\mathbf{t}=\mathbf{4} \mathbf{h}$ after induction on } \\
\cline { 3 - 5 } & & galA & poly-galA & pectin \\
\hline An07g00780 & Major facilitator superfamily strong similarity to monocarboxylate transporter & 23.10 & 9.98 & 5.27 \\
An14g04280 & Major facilitator superfamily strong similarity to hexose transporter & 26.53 & 22.74 & 27.95 \\
An03g01620 & Major facilitator superfamily strong similarity to hexose transporter & 6.50 & 1.345 & 37.54 \\
\hline
\end{tabular}


Table 2 Primers used in vector construction

\begin{tabular}{ll}
\hline Primer & Sequence \\
\hline JS_gatC_FW & 5'-GAGAATGCATATGTCTGAGCCTAAGAACCAGC-3' \\
JS_gatC_RV & 5'-GAGAGCGGCCGCTCATATTTTGCTCGTATTCC-3' \\
JS_gatCmut2_FW & 5'-GTTGCCAAAGTGGGAGACCTGCAAACCCTGGGTC-3' \\
JS_gatCmut2_RV & 5'-GACCCAGGGTTGCAGGTCTCCCACTTGGCAAC-3' \\
JS_XInDP_FW & 5'-AGTCAATCGGTCATTCTCCG-3' \\
JS_gatA_RV & 5'-CTCTTGGAGGACGCAAAACC-3' \\
JS_gatB_RV & 5'-CATGGAAGCGGTGATCTAGG-3' \\
\hline
\end{tabular}

water. The presence of An14g04280, An03g01620 and An07g00780 expression constructs was confirmed by PCR using the JS_XlnDp_FW primer, binding to the promoter region of the construct, and JS_gatA_RV, JS_gatB_RV or JS_gatC_RV specifically binding to the complementary strand in the corresponding coding region. Transformants with confirmed gene constructs were re-plated on complete medium. Spores are harvested after 4 days of growth at $30^{\circ} \mathrm{C}$.

\section{Growth in shake flasks}

Strains were grown in duplicate in $200 \mathrm{~mL}$ PM medium (1.2 $\mathrm{g} \mathrm{NaNO}_{3}, 0.5 \mathrm{~g} \mathrm{KH}_{2} \mathrm{PO}_{4}, 0.2 \mathrm{~g} \mathrm{MgSO}_{4} 7 \mathrm{H}_{2} \mathrm{O}, 0.5 \mathrm{~g}$ Yeast extract and $40 \mu \mathrm{g}$ Vishniac per liter) (Ruijter et al. 1999) with $91 \mathrm{mM}$ sorbitol and $9 \mathrm{mM} \mathrm{D}$-galacturonic acid or $100 \mathrm{mM}$ of the synthetic cell wall hydrolysate (SCH) (Carpita and Gibeaut 1993) (Table 3) as a carbon source in $1 \mathrm{~L}$ flasks. For inoculation, a final concentration of $1 \cdot 10^{6}$ spores per $\mathrm{mL}$ was used. Induction of the $x \ln D$ promoter with $10 \mathrm{mM} \mathrm{D}$-xylose was done at $\mathrm{t}=0$, 18 hours after inoculation (van der Veen et al. 2009). Transformants were grown for 5 days at $30^{\circ} \mathrm{C}$ and $250 \mathrm{rpm}$. Medium samples were taken by filtration of $2 \mathrm{ml}$ of the culture broth through a 5-micron pore size nylon filter. Biomass samples were obtained by washing of the retentate with demineralized water and flash freezing using liquid nitrogen. The samples were taken at $\mathrm{T}=-18 \mathrm{~h}, 0 \mathrm{~h}, 6 \mathrm{~h}, 30 \mathrm{~h}, 54 \mathrm{~h}$ for the first growth

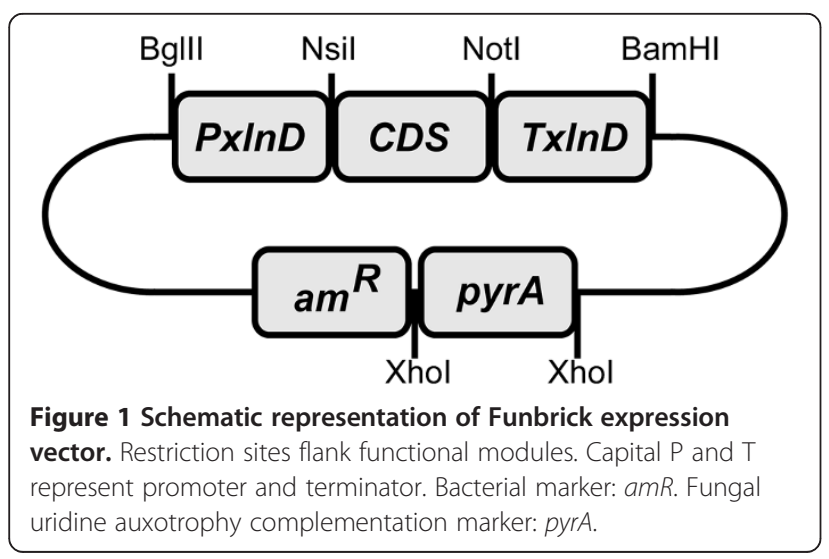

Table 3 Composition of synthetic cell wall hydrolysate (SCH)

\begin{tabular}{ll}
\hline Compound \% & Concentration $\mathbf{( g / l )}$ \\
\hline D-glucose; 65\% & 13 \\
D-xylose; 20\% & 4 \\
D-galacturonic acid; 10\% & 2 \\
L-arabinose; 3\% & 0.6 \\
D-galactose; 1\% & 0.2 \\
D-mannose; 1\% & 0.2 \\
\hline
\end{tabular}

experiment on D-galacturonic acid. For the second Dgalacturonic acid growth experiment, samples were taken at $\mathrm{T}=-18 \mathrm{~h}$, each hour from $\mathrm{T}=0 \mathrm{~h}$ to $\mathrm{T}=10 \mathrm{~h}$, $24 \mathrm{~h}, 30 \mathrm{~h}, 54 \mathrm{~h}$ and $78 \mathrm{~h}$. For the growth experiment with $\mathrm{SCH}$ as a carbon source, samples were taken from $\mathrm{T}=0 \mathrm{~h}$ with steps of 24 and 6 hours: $\mathrm{T}=0 \mathrm{~h}, \mathrm{~T}=24 \mathrm{~h}$, $\mathrm{T}=30 \mathrm{~h}, \mathrm{~T}=48 \mathrm{~h}, \mathrm{~T}=54 \mathrm{~h}$.

\section{Growth in fermentors}

Strains were grown in duplicate in $500 \mathrm{~mL}$ PM medium (Ruijter et al. 1999) with $100 \mathrm{mM}$ sorbitol as a carbon source in $1 \mathrm{~L}$ flasks. For inoculation, a final concentration of $1 \cdot 10^{6}$ spores per $\mathrm{mL}$ was used. Cultures were incubated for 18 hours at $30^{\circ} \mathrm{C}$ with $250 \mathrm{rpm}$ orbital shaking. Mycelium was aseptically harvested by filtering over a sterile nylon cloth, washed with PM without carbon source and transferred to $1 \mathrm{~L}$ fermentors. Fermentors contained $750 \mathrm{ml} \mathrm{PM}$ with $50 \mathrm{mM}$ D-xylose and $50 \mathrm{mM}$ D-galacturonic acid, adjusted to pH6. Air was flushed at a stirrer speed of $600 \mathrm{rpm}$. Medium and biomass samples were taken as previously described, with an additional sampling of mycelium from $10 \mathrm{ml}$ broth volume for enzymatic assays. Carbon dioxide and oxygen concentrations in off-gas were measured as well as $\mathrm{pH}$.

\section{HPLC analysis}

High-pressure liquid chromatography (HPLC) was used to determine the extracellular concentrations of D-glucose, L-sorbitol, D-xylose, citric acid and D-galacturonic acid in the culture broth samples. A Shodex KC-811 column was used at $30^{\circ} \mathrm{C}$ that was eluted with $0.01 \mathrm{~N} \mathrm{H}_{2} \mathrm{SO}_{4}$ at a flow rate of $0.8 \mathrm{~mL} \mathrm{~min}{ }^{-1}$. A refractive index detector (Spectrasystem RI-150, sample frequency $5.00032 \mathrm{~Hz}$ ) and a UV-VIS detector (Spectrasystem UV1000, $\lambda=$ $210 \mathrm{~nm}$ ) were used for detection of the eluting compounds. Crotonate at a concentration of $6 \mathrm{mM}$ was used as an internal standard.

\section{Enzyme assay}

To determine the activity of the $\mathrm{D}$-galacturonic acid metabolism, the first step in the enzymatic conversion, D-galacturonic acid to L-galactonic acid, was measured. D-galacturonic acid reductase assay based on conversion 
of NADPH to NADP ${ }^{+}$, previously described by Kuorelahti et al., was applied (Kuorelahti et al. 2005). $20 \mathrm{mg}$ of frozen mycelium was added to $400 \mu \mathrm{l}$ of extraction buffer (100 mM phosphate buffer pH 7.0, 0.1 mM EDTA, $1 \mathrm{mM}$ DTT and fungal protease inhibitor cocktail) in lysing matrix $\mathrm{C}$ tubes (MP biomedicals) and disrupted at level 6 for 30 seconds in a bead beater (MP fastprep-24). Cell debris was removed by centrifugation and supernatant was used as cell extract. $25 \mu \mathrm{l}$ of cell extract was added to $200 \mu \mathrm{l}$ of assay buffer $(100 \mathrm{mM}$ sodium phosphate buffer $\mathrm{pH} 7.0,0.25 \mathrm{mM} \mathrm{NADPH}$ ) and reaction was started by the addition of $25 \mu \mathrm{l}$ of substrate (1 M D-galacturonic acid $\mathrm{pH}$ 6). Decrease of absorbance at $340 \mathrm{~nm}$ was measured on a platereader (Biotek Synergy) in parallel with sample controls, for which $25 \mu$ l of buffer was added. Background activity of sample control without D-galacturonic acid was substracted from sample measurements with Dgalacturonic acid. Protein content was determined by photometric assay (Peterson 1977).

\section{Results}

Strains that overexpress GatA have increased D-galacturonic acid uptake in shakeflask cultures

To study the effect of the expression of the putative D-galacturonic acid transporter encoding gene, the Dgalacturonic acid concentration in the medium was measured during growth. A faster uptake of D-galacturonic acid from the medium was observed for the cultures with the An14g04280 overexpression strains (transformant) in comparison to the NW185 PYR $\mathrm{A}^{+}$control strain. At 6 hours after induction, the strains that overexpress An14g04280 had taken up over 50\% of D-galacturonic acid present at the start of the cultivation, while no Dgalacturonic acid had been taken up by the control strain. The strains containing the other constructs did not show any difference in D-galacturonic acid uptake in comparison to the NW185 PYR A ${ }^{+}$control strain. The effect of the An14g04280 overexpression strain is most pronounced between time points 6 and $30 \mathrm{~h}$.

A second experiment was performed to get a more time resolved determination of the uptake of D-galacturonic acid by the best performing transformant strain (JS013). The difference in D-galacturonic acid uptake starts to become evident from 4 hours after induction, with the highest contrast between 5 and 6 hours after induction (Figure 2).

To study the effect of An14g04280 in the uptake of D-galacturonic acid during growth on more complex mixed sugar substrates, JS013 was grown in the presence of a substrate mix (SCH), mimicking the composition of a plant cell wall hydrolysate (Carpita and Gibeaut 1993). When comparing the uptake of the three main components $\mathrm{D}$-glucose, D-xylose and D-galacturonic acid between the transformants and the control strain, a clear

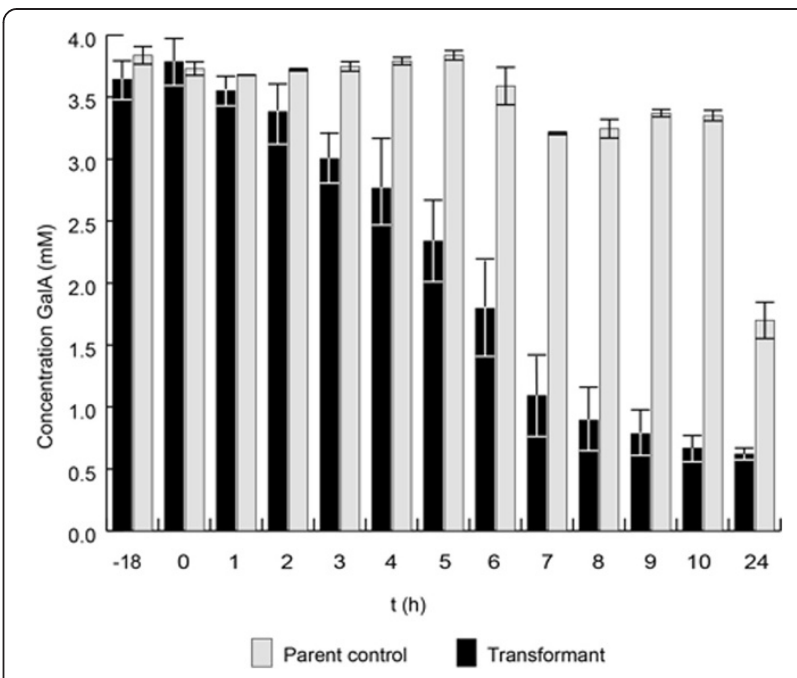

Figure 2 Concentration of GalA in the medium during growth on sorbitol and GalA. Induction of expression system with D-xylose at $\mathrm{T}=0$. Overexpression strains of gatA (number of replicates $=4$ ) in comparison to the control NW185 PYR A+ (number of replicates =2).

difference is found (Figure 3a and b). Till 24 hours after inoculation, substrate uptake is similar for all strains. After 30 hours, differences in D-galacturonic acid and D-xylose uptake become evident. At time point 48 hours, the control strain has almost depleted the D-xylose and most of the D-galacturonic acid remains in the medium, while the transformant has consumed $80 \%$ of the Dgalacturonic acid and most D-xylose remains in the medium. While D-glucose and D-xylose are depleted in the control culture after 54 hours, depletion of D-xylose in the transformant cultures can only be seen at time point $72 \mathrm{~h}$.

The biomass formed and the citrate produced were measured for the An14g04280 overexpression strain and the control strain. Recovery of substrate in biomass and citrate produced was 35\% for the control strain and 30\% for the transformants. It was found that for the overexpression strain $30 \%$ of this is citrate and $70 \%$ is biomass, while for the control strain, $10 \%$ is citrate and $90 \%$ is biomass (Figure 4). Cmoles that are not accounted for are assumed to be $\mathrm{CO}_{2}$ and enzyme production (not measured). For these calculations the generalized molecular formula for fungal biomass $\mathrm{CH}_{1.72} \mathrm{O}_{0.55} \mathrm{~N}_{0.17}$ was used (Carlsen and Nielsen 2001).

Growth of transporter overexpression strains in fermentors When strains were grown in the presence of equimolar concentration of D-xylose and D-galacturonic acid in fermentors, preferential uptake of D-galacturonic acid over D-xylose of JS013 in comparison to NW185 PYR A ${ }^{+}$control strain is observed. This is deduced from measured concentrations of D-galacturonic acid and D-xylose, but also from an increase of the $\mathrm{pH}$ of the medium, after D- 


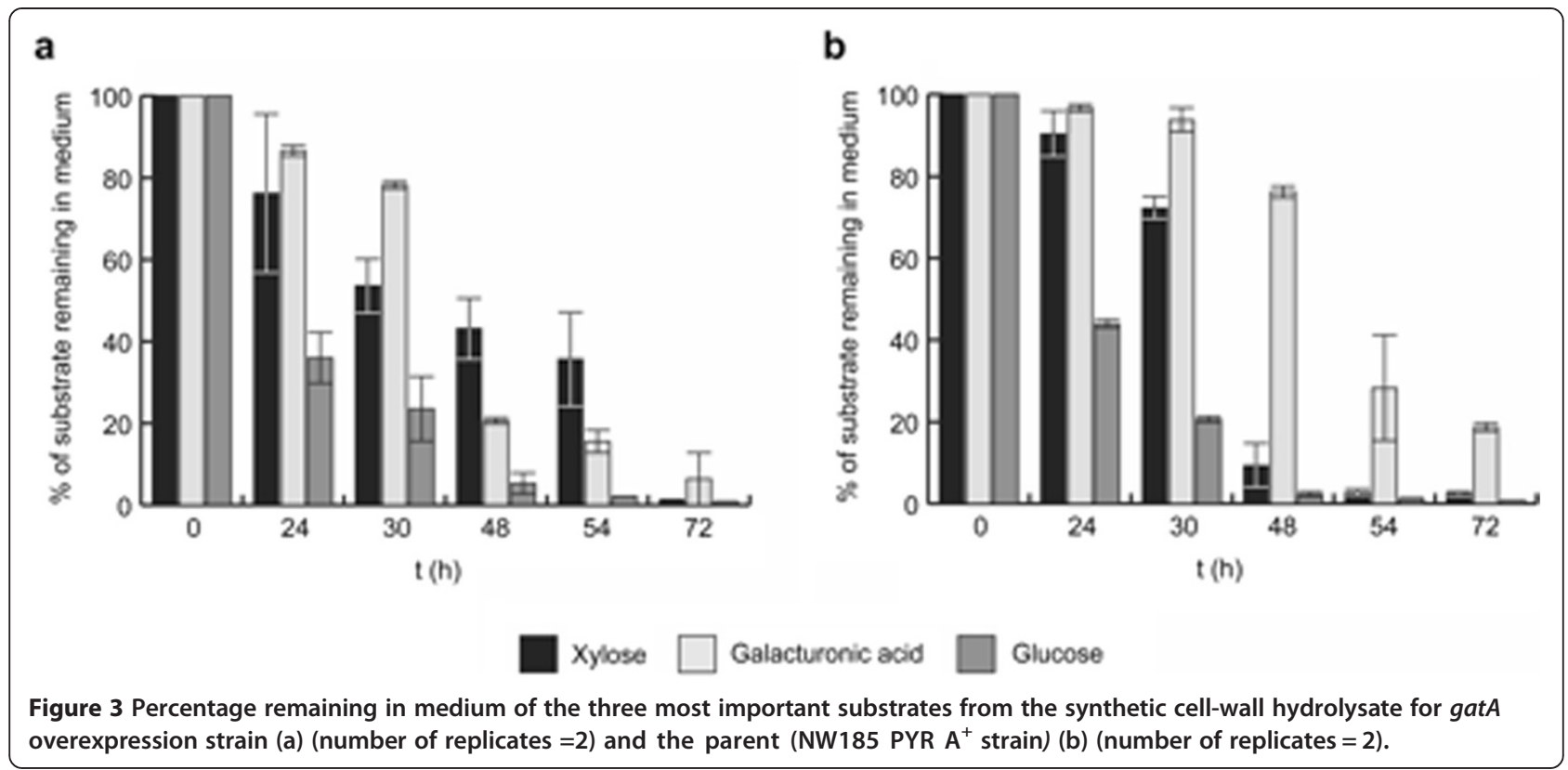

galacturonic acid is taken up (Figure 5). Increased activity of the D-galacturonic acid metabolic pathway is observed for JS013 transformant strain in comparison to the control. For the first 4 hours after transfer to the fermentors, no difference in D-galacturonic acid reductase activity could be seen. 8 hours after transfer, however, specific activity of JS013 is two-fold higher than that of the control strain. The concentration of $\mathrm{CO}_{2}$ in the offgas went up to 0.35 percent by volume in the first two hours and slowly down to 0.2 percent by volume in the next
6 hours, while ambient concentration was 0.04 percent by volume (Figure 6).

\section{Phylogenetic analysis of GatA}

In Botrytis cinerea and Neurospora crassa, D-galacturonic acid transporter proteins have been functionally identified (Benz et al. 2014; Zhang et al. 2013). After import, Dgalacturonic acid is catabolized by three key enzymes: D-galacturonic acid reductase, L-galactonate dehydratase and 2-keto-3-deoxy-galactonate aldolase, in A. niger
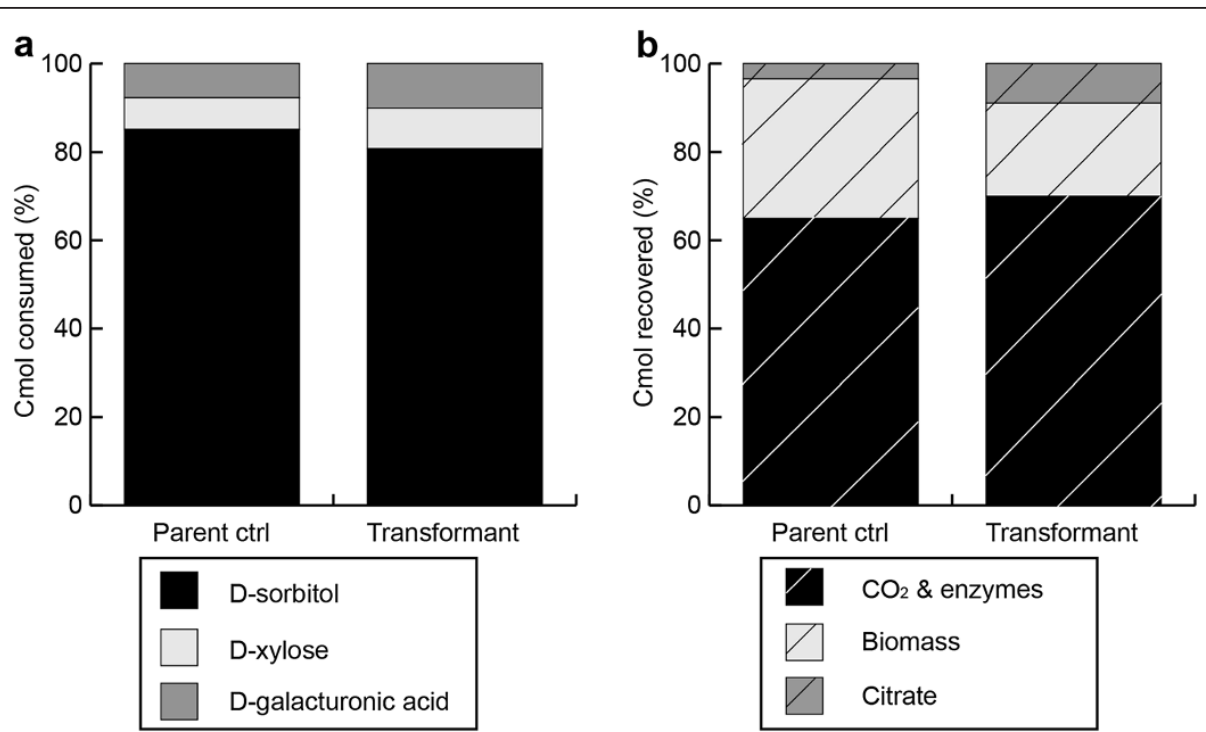

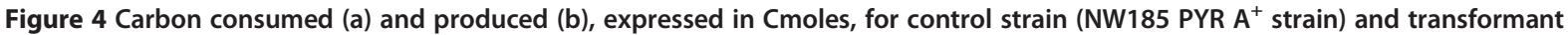
JS013 after $\mathbf{7 2} \mathbf{h}$ of growth on SCH medium. Samples taken from direct cultures, D-xylose in the mixed substrate medium serves as an inducer of the $x \ln D$ promoter. Totals represent 0.1 Cmoles. 


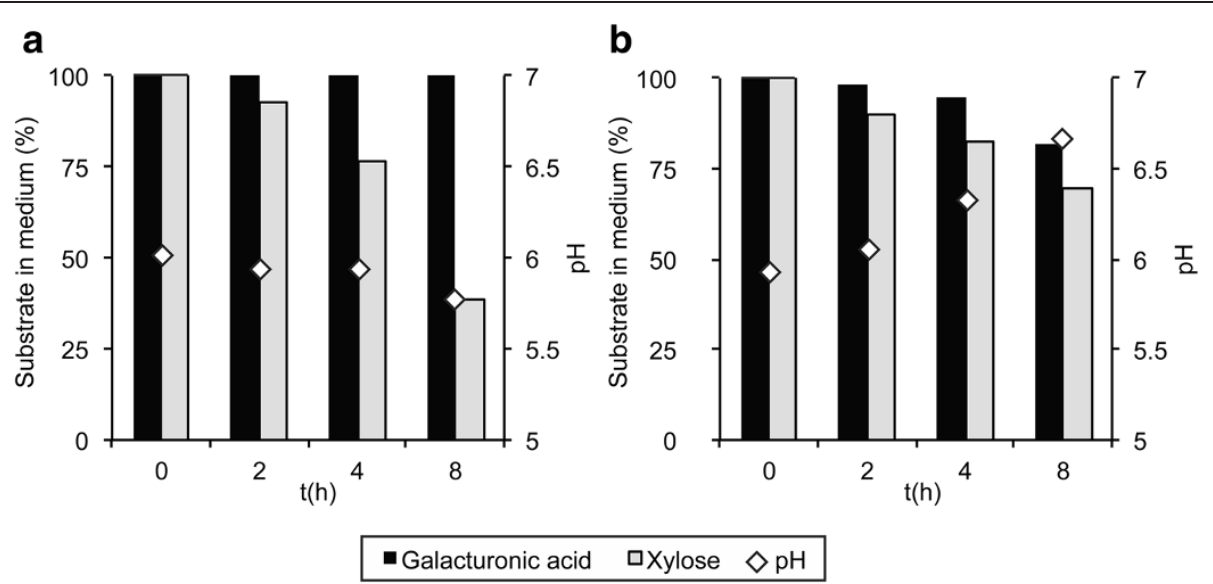

Figure 5 Substrate remaining in culture medium and pH during growth in fermentors of the control, (NW185 PYR A ${ }^{+}$strain) (a) and overexpression strain, JS013 (b). The strains were pre-grown and mycelium was transferred at T=0 to fermentors containing D-xylose and D-galacturonic acid as substrates.

encoded by gaaA, gaaB and gaaC respectively. Orthologs of the $g a a A$ and $g a a C$ genes have been identified in $B$. cinerea and $N$. crasssa and 16 other fungal species that all have a conserved bidirectional organization of their gaaA - gaaC promoter region (Martens-Uzunova and Schaap 2008). For each of these 18 species a bidirectional best BLAST hits procedure (Overbeek et al. 1999) yielded a putative GatA ortholog. Orthologous amino acid sequences were aligned with Clustal (Larkin et al. 2007) and a phylogenetic tree was constructed (Figure 7). All orthologs have 12 predicted transmembrane helices (Viklund and Elofsson 2004) separating two interacting domains and the substrate binding domain (Yan 2013) (Figure 8). In these three domains the three characterized Dgalacturonic acid transporters share 18 conserved residues not present in the A. niger MstA D-glucose transporter protein sequence, which was used as an outgroup. The

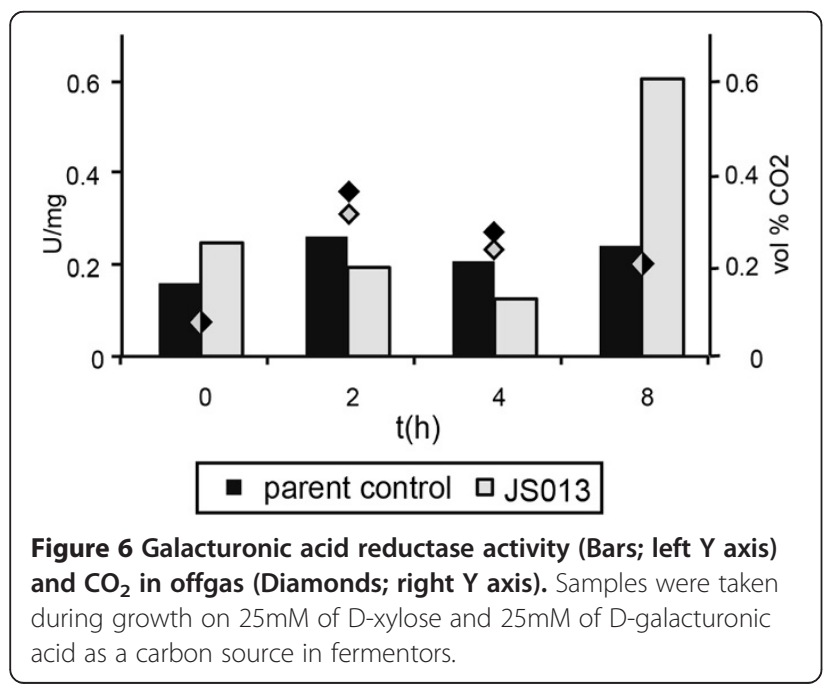

presence of this motif was used to assess the other 16 putative orthologs. Fifteen putative orthologs shared 8 of these residues, excluding the Fusarium verticilliodes putative ortholog which clusters with the D-glucose transporter MstA (Figure 7) and can be a transporter for another sugar.

\section{Discussion}

Three genes that potentially encode the D-galacturonic acid transporter in A. niger are investigated. A. niger transformants that overexpress the An14g04280 gene under control of the D-xylose induced $x \ln D$ promoter show a significant increase in D-galacturonic acid uptake. From this we conclude that this gene, gatA, encodes for the D-galacturonic acid transporter, GatA.

By analysis of the amino acid sequence using the $\alpha-$ helical transmembrane protein topology prediction software (PRODIV-TNHMM) (Viklund and Elofsson 2004) GatA is predicted to be part of the Major Facilitator Superfamily (MFS). MFS transporter proteins consist of 12 transmembrane helices and have both $\mathrm{C}$ - and $\mathrm{N}$-termini located in the cytoplasm.

This study shows that the overexpression of gat $A$, using a D-xylose inducible promoter, leads to differences in the uptake of sugars when the strains are grown on various mixed sugar substrates. GatA overproducing strains preferentially use D-galacturonic acid over Dxylose, while the wild type strains prefer D-xylose. Dxylose is used for overexpression of the GatA transporter in all growth experiments and it is also used as a substrate. However, the main carbon source present in the medium is sorbitol, a non-inducing, non-repressing carbon source. Our extensive previous studies have shown that in this condition induction of expression occurs at 


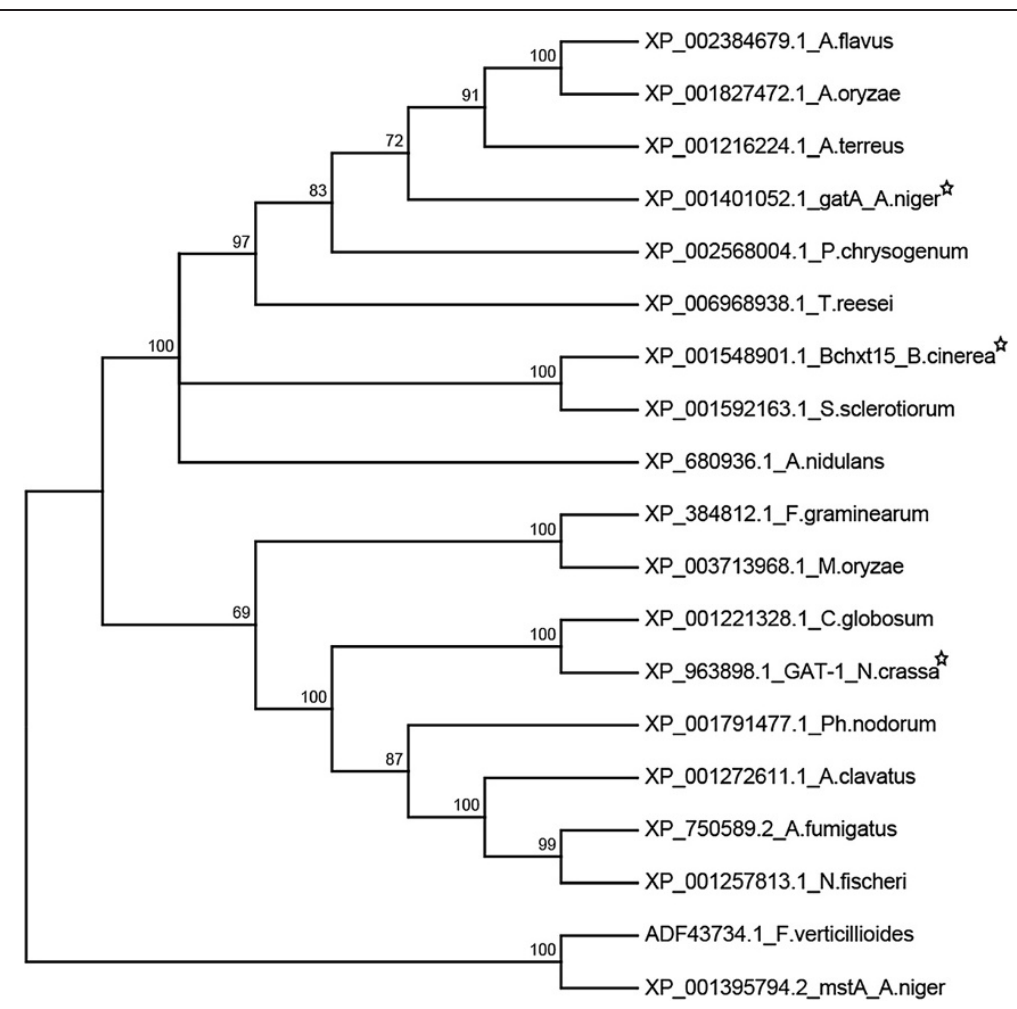

Figure 7 Neighbor-joining tree of GatA and 17 putative orthologs, constructed with 1000 bootstrap replicates using MEGA6.06 (Tamura et al. 2013), and a characterized high-affinity glucose transporter protein (mstA_A.niger) as an outgroup (vanKuyk et al. 2004). Stars indicate the three currently characterized D-galacturonic acid transporters. Bootstrap values are indicated at the branch-points. Labels indicate Protein Accession numbers followed by species abbreviations. Abbreviations: Aspergillus clavatus; A. clavatus, Aspergillus flavus; A. flavus, Aspergillus fumigatus; A. fumigatus, Aspergillus nidulans; A. nidulans, Aspergillus niger; A. niger, Aspergillus oryzae; A. oryzae, Aspergillus terreus; A. terreus, Botrytis cinerea; B. cinerea, Chaetomium globosum; C. globosum, Fusarium verticilliodes; F. verticilliodes, Neosartorya fischeri; N. fischeri, Neurospora crassa; N. crassa, Penicillium chrysogenum; P. chrysogenum, Phaeosphaeria nodorum; Ph. nodorum, Sclerotinia sclerotiorum; S. sclerotiorum, Trichoderma reesei; T. reesei.

concentrations of 0.1 to $50 \mathrm{mM}$ D-xylose (van der Veen et al. 2009; Mach-Aigner et al. 2012).

The increased D-galacturonic acid uptake of the transformant was not reflected in the basal GaaA enzyme activity during the first hours of growth on D-xylose and D-galacturonic acid. It is, however, reflected in an increased GaaA enzyme activity after 8 hours. This time delay suggests that GaaA enzyme activity is not limiting D-galacturonic acid uptake and metabolism during the first few hours of growth on these substrates and that regulation of expression of GaaA is taking place "at the gate", via import of D-galacturonic acid. The repression

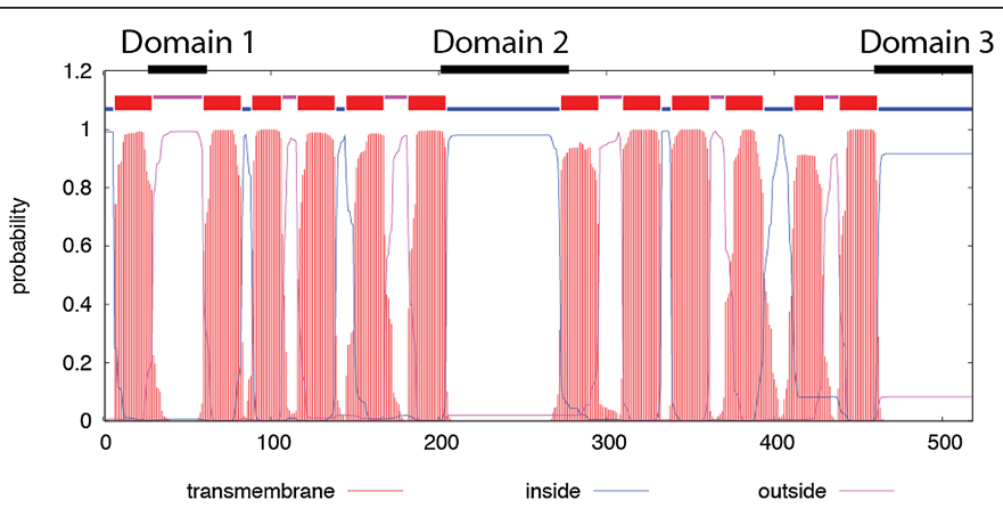

Figure 8 Transmembrane domain prediction and indication of the two interacting domains $(1,3)$ and the putative substrate binding domain (2) used for comparison of the putative GatA orthologs (Viklund and Elofsson 2004). 
of induction of GaaA in the presence of D-xylose in the parent strain, is bypassed by an increased influx of substrate in the GatA overexpressing strain, suggesting that the endogenous $\mathrm{D}$-galacturonic acid catabolic pathway is controlled by a pathway intermediate such as L-galactonate or keto-deoxy-L-galactonate as has been suggested for T. reesei (Kuivanen et al. 2012).

Several repressing and inducing regulatory systems are known to be functioning in Aspergillus niger. The glucose carbon catabolite repressor $c r e A$ is the most studied and is known to be dominant in most cases (de Vries et al. 1999). The promoter region of the gatA gene shows two consensus sequences for binding of this protein, which suggests that D-glucose is repressing the expression of the endogenous gene. The $x \ln R$ xylanolytic induction system is also well studied and an inducer consensus binding sequence is known (van Peij et al. 1998). This consensus sequence can not be found in the upstream region of the endogenous gatA gene and it is therefore not induced by the presence of D-xylose. Additionally, GatA expression has been found to be stricktly coregulated with D-galacturonic acid catabolic enzymes and a number of extracellular galacturonases (Martens-Uzunova and Schaap 2008). The regulator of the D-galacturonic acid metabolism, however, remains unknown for now.

We have investigated the application of our findings by growing our strains on a synthetic medium mimicking a plant cell wall hydrolysate. Under these conditions the gatA overexpressing strains preferentially use Dgalacturonic acid over D-xylose. In these experiments it was found that GatA overexpression strains had a higher citric acid yield. While the effect seems pronounced on a simulated hydrolysate substrate, further experiments are needed to study the benefit on second generation feedstocks with high D-galacturonic acid content like sugar beet pulp to investigate the potential of GatA in biotechnological applications.

\section{Competing interests}

The authors declare that they have no competing interests.

\section{Authors' contributions}

JS and LG designed the study. JS and MS designed and performed the experimental work. PS contributed to the design and execution of the phylogenetic analysis. JS wrote the manuscript PS and LG participated herein. All authors read and approved the submission of the manuscript.

\section{Acknowledgements}

This work has been carried out on the basis of a grant in the framework of the BE- BASIC program F01.011 Transport processes in the production of organic acids by Aspergillus niger. We would like to thank Tom Schonewille for his assistance with the analysis equipment.

Received: 6 June 2014 Accepted: 8 August 2014

Published online: 23 August 2014

\section{References}

Ángel Siles López J, Li Q, Thompson IP (2010) Biorefinery of waste orange peel. CRC Cr Rev Biotechn 30:63-69, doi:10.3109/07388550903425201
Arnaud MB, Cerqueira GC, Inglis DO, Skrzypek MS, Binkley J, Chibucos MC, Crabtree J, Howarth C, Orvis J, Shah P, Wymore F, Binkley G, Miyasato SR, Simison M, Sherlock G, Wortman JR (2012) The Aspergillus Genome Database (AspGD): recent developments in comprehensive multispecies curation, comparative genomics and community resources. Nucleic Acids Res 40:D653-D659

Benz J, Protzko RJ, Andrich JM, Bauer S, Dueber JE, Somerville CR (2014) Identification and characterization of a galacturonic acid transporter from Neurospora crassa and its application for Saccharomyces cerevisiae fermentation processes. Biotechnol Biofuels 7:20-14, doi:10.1111/j.1567-1364.2009.00523.x

Carlsen M, Nielsen J (2001) Influence of carbon source on alpha-amylase production by Aspergillus oryzae. Appl Microbiol Biotechnol 57:346-349

Carpita NC, Gibeaut DM (1993) Structural models of primary cell walls in flowering plants: consistency of molecular structure with the physical properties of the walls during growth. Plant J 3:1-30

de Vries RP, Visser J, de Graaff LH (1999) CreA modulates the XInR-induced expression on xylose of Aspergillus niger genes involved in xylan degradation. Res Microbiol 150(4):281-285

Gielkens MMC, Dekkers E, Visser J, de Graaff LH (1999) Two cellobiohydrolaseencoding genes from Aspergillus niger require D-xylose and the xylanolytic transcriptional activator XInR for their expression. Appl Environ Microbiol 65:4340-4345

Howard RL, Abotsi E, van Rensburg EJ, Howard S (2003) Lignocellulose biotechnology: issues of bioconversion and enzyme production. Afr J Biotechnol 2:602-619, doi:10.4314/ajb.v2i12.14892

Kuivanen J, Mojzita D, Wang Y, Hilditch S, Penttila M, Richard P, Wiebe MG (2012) Engineering filamentous fungi for conversion of D-galacturonic acid to L-galactonic acid. Appl Environ Microbiol 78:8676-8683, doi:10.1128/ AEM.02171-12

Kuorelahti S, Kalkkinen N, Penttil M, Londesborough J, Richard P (2005) Identification in the mold Hypocrea jecorina of the first fungal D-galacturonic acid reductase. Biochemistry 44:11234-11240, doi:10.1021/bi050792f

Kusters-van Someren MA, Harmsen JA, Kester HC, Visser J (1991) Structure of the Aspergillus niger pelA gene and its expression in Aspergillus niger and Aspergillus nidulans. Curr Genet 20:293-299

Larkin MA, Blackshields G, Brown NP, Chenna R, McGettigan PA, McWilliam H, Valentin F, Wallace IM, Wilm A, Lopez R, Thompson JD, Gibson TJ, Higgins DG (2007) Clustal W and Clustal X version 2.0. Bioinformatics 23:2947-2948, doi:10.1093/bioinformatics/btm404

Mach-Aigner AR, Omony J, Jovanovic B, van Boxtel AJB, de Graaff LH (2012) D-Xylose concentration-dependent hydrolase expression profiles and the function of CreA and XInR in Aspergillus niger. Appl Environ Microbiol 78(9):3145-3155, doi:10.1128/AEM.07772-11

Martens-Uzunova ES, Schaap PJ (2008) An evolutionary conserved D-galacturonic acid metabolic pathway operates across filamentous fungi capable of pectin degradation. Fungal Genet Biol 45:1449-1457, doi:10.1016/j.fgb.2008.08.002

Micard V, Renard CMGC, Thibault JF (1996) Enzymatic saccharification of sugar-beet pulp. Enzyme Microb Technol 19:162-170, doi:10.1016/ 0141-0229(95)00224-3

Overbeek R, Fonstein M, D'Souza M, Pusch GD, Maltsev N (1999) The use of gene clusters to infer functional coupling. Proc Natl Acad Sci U S A 96:2896-2901

Peterson GL (1977) A simplification of the protein assay method of Lowry et al. which is more generally applicable. Anal Biochem 83:346-356, doi:10.1016/ 0003-2697(77)90043-4

Pfaffl MW (2001) A new mathematical model for relative quantification in real-time RT-PCR. Nucleic Acids Res 29:45e-45, doi:10.1093/nar/29.9.e45

Ruijter GJG, van de Vondervoort PJI, Visser J (1999) Oxalic acid production by Aspergillus niger: an oxalate-non-producing mutant produces citric acid at $\mathrm{pH}$ 5 and in the presence of manganese. Microbiology 145(Pt 9):2569-2576

Tamura K, Stecher G, Peterson D, Filipski A, Kumar S (2013) MEGA6: molecular evolutionary genetics analysis version 6.0. Mol Biol Evol 30:2725-2729, doi:10.1093/molbev/mst197

van den Brink J, de Vries RP (2011) Fungal enzyme sets for plant polysaccharide degradation. Appl Microbiol Biotechnol 91:1477-1492, doi:10.1007/s00253011-3473-2

van der Veen D, Oliveira JM, van den Berg WAM, de Graaff LH (2009) Analysis of variance components reveals the contribution of sample processing to transcript variation. Appl Environ Microbiol 75:2414-2422

van Dijck PWM, Selten GCM, Hempenius RA (2003) On the safety of a new generation of DSM Aspergillus niger enzyme production strains. Regul Toxicol Pharmacol 38:27-35, doi:10.1016/S0273-2300(03)00049-7 
van Peij NNME, Visser J, de Graaff LH (1998) Isolation and analysis of $x / n R$, encoding a transcriptional activator co-ordinating xylanolytic expression in Aspergillus niger. Mol Microbiol 27:131-142, doi:10.1046/j.1365-2958.1998.00666.x

vanKuyk PA, Diderich JA, MacCabe AP, Hererro O, Ruijter G, Visser J (2004) Aspergillus niger mstA encodes a high-affinity sugar/H + symporter which is regulated in response to extracellular pH. Biochemical J 379:375-383

Viklund $\mathrm{H}$, Elofsson A (2004) Best a-helical transmembrane protein topology predictions are achieved using hidden Markov models and evolutionary information. Protein Sci 13:1908-1917, doi:10.1110/ps.04625404

Willke T, Vorlop KD (2001) Biotechnological production of itaconic acid. Appl Microbiol Biotechnol 56:289-295

Yan N (2013) Structural advances for the major facilitator superfamily (MFS) transporters. Trends Biochem Sci 38:151-159, doi:10.1016/j.tibs.2013.01.003

Zhang L, Hua C, Stassen JHM, Chatterjee S, Cornelissen M, van Kan JAL (2013) Genome-wide analysis of pectate-induced gene expression in Botrytis cinerea: Identification and functional analysis of putative D-galacturonate transporters. Fungal Genet Biol, doi:10.1016/.jfgb.2013.10.002

doi:10.1186/s13568-014-0066-3

Cite this article as: Sloothaak et al:: Overexpression of the Aspergillus niger GatA transporter leads to preferential use of D-galacturonic acid over D-xylose. AMB Express 2014 4:66.

\section{Submit your manuscript to a SpringerOpen ${ }^{\circ}$ journal and benefit from:}

- Convenient online submission

- Rigorous peer review

- Immediate publication on acceptance

- Open access: articles freely available online

- High visibility within the field

- Retaining the copyright to your article 